\title{
The theater as a motivational tool of education in oral health of elderly
}

\section{Introduction}

Health promotion has a broad approach which evolves prevention, habit changes, education, social changes and self-health control, considering that those factors depend on the health professional philosophy and ability, as well as the social space where the activity is performed. ${ }^{1}$ Besides that, the healing assistance model, which has high costs and the low epidemiologic impact, are routinely used in various populations, resulting in a big challenge to Brazilians dental surgeons about oral health education. ${ }^{2}$

The elderly population has a high prevalence in dentistry complications, which results in pathologies accumulated during life, due an oral health deficiency, lack of orientation and interest, besides the difficulty in the access to dentistry assistance services, which leads to high edentulism. ${ }^{3}$ However, there is a worldwide trend to maintain the teeth in the aging population, which increases the complexity in self-care and professional attention with the plurality of clinics cases, and the most effective way to modify the self-perception in health

promotion is to give information and basic guidance to the population, extending to oral health. ${ }^{3}$

Educational programs that use activities with theoretical content and participative dimensions, such as pedagogical games and competitions have a fundamental importance in the habit changes in oral health. ${ }^{4}$ When used isolated, the theoretical instructions on oral hygiene are not enough to allow behavioral changes in health. ${ }^{5}$ However, in the educational process the professional should have a cautious approach, a conviction in the significance of the health promotion messages, respecting the fact that people have their own values and priorities, avoiding imposing concepts and knowing how to access the patient expectations. ${ }^{6}$

Once those values, beliefs and oral health habits are cultural elements and decisive in people behavior in relation to oral health, it is important to emphasize how the culture influences the patients' basic ideas regarding health to effectively treat them and improve oral health conditions, primarily connected to the values attributed to it by the population.?

Playful activity has shown the capacity to involve the viewer in the educational process and to promote informal and humanistic communication, ${ }^{8}$ it can promote motivation with speeches, games, theater or book reading, addressing health, positively influencing patients' lives, providing welfare, emotional feelings, nostalgia, and self-esteem. ${ }^{9}$ The theater practice has shown an efficient strategy to help the therapeutic process of hospitalized patients, ${ }^{10}$ as well used in health education as a bridge between popular and scientific knowledge ${ }^{11}$. The theater has also shown its significance to improve human relationships, allowing health professionals to perceive patients in a broad way. ${ }^{12}$

Therefore, scenic art offers the appreciation in the individual knowledge favoring a more participative attitude and a better life history, knowledge and experience ${ }^{12}$ and there are no programs adopting theater as a tool of education on oral health for elderly, being this instrument more applied in teenagers ${ }^{4}$ and children. ${ }^{13}$
Volume 3 Issue 5 - 2018 Montandon AAB, Gregorio A, Saggioro ACB,
Pinelli LAP
Araraquara School of Dentistry, Universidade Estadual Paulista
(UNESP), Brazil

Correspondence: Lígia Antunes Pereira Pinelli,Associate Professor, Araraquara School of Dentistry, Universidade Estadual Paulista (UNESP), Brazil, Tel 55I6330I- 63।3, Email HYPERLINK “mailto:ligia@foar.unesp.br”ligia@foar unesp.br

Received: September 27, 2018 | Published: October 03, 2018

Due to the relevance of the educative approach in the context of health promotion, it is fundamental to know methods that are proper to elderly education, such as theater presentation. So, the aim of this study was to know the learning capacity on concepts involving health aging by a theater presentation to an independent elderly group. The null hypothesis was that theater presentations are not capable to incorporate new concepts on oral health and aging to the target population.

\section{Materials and methods}

\section{Study population and ethical considerations}

The target population was constituted by 100 independent elderly residents in Araraquara, São Paulo, Brazil, with 60 years old or more, of both genders, recruited in organized groups of elderly and in the waiting room of the clinics of Araraquara School of DentistryUNESP. The study was approved by the ethics and research committee of the same institution and all participants signed a free consent term accepting their voluntary participation.

\section{Methods of the theatrical production}

A script regarding oral health was composed of characters that allow self-identification with the target group, using a distinctive language and similar behavior. Topics connected with aging and its relation with health, especially oral health and its significance in general welfare, besides specifics concepts on habits, oral hygiene, and disease based on Montandon et al. ${ }^{14}$ were the text foundation.

The theater piece entitled "A day like any other" was composed with three main characters and two supporting characters, following the context: Mrs. Ambrosia is the main character, a widow lady that just arrived home after traveling to her hometown and that portrays the memory of her married life, allowing that the audience identify themselves with the character before approaching oral health. A suitcase with objects is used to represent her memories and outstanding events, including the loss of her teeth. To deepen 
the exposure of the main character, two supporting character were used for the first ball dance of the couple: Nilse, the neighbor, focus even more the familiarity with elderly and stimulate the characters to explain questions about the proposed theme to a third character, Luiza, a young lady that helps in the house, is the one who answers the questions about oral health. Luiza represents the caregiver or the family member of the elderly and makes them reflect on the help of younger people (Figure 1).

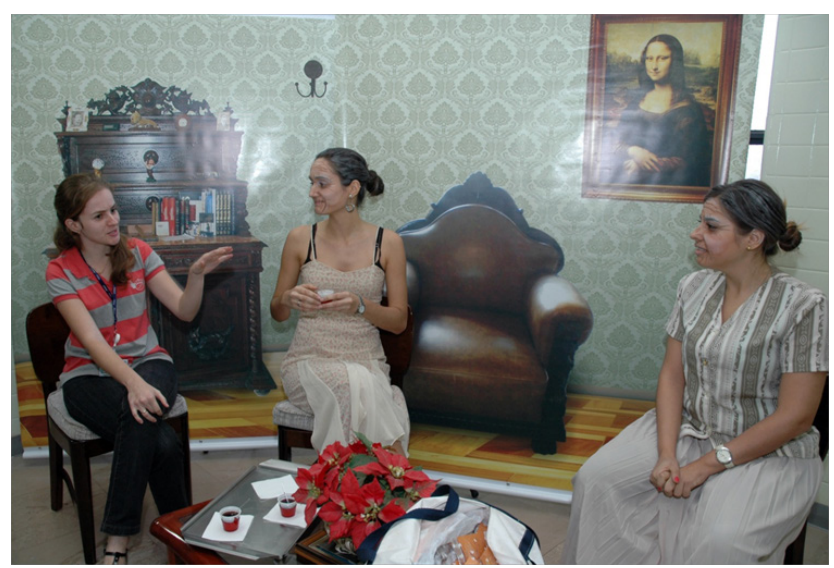

Figure I Luiza represents the caregiver or the family member of the elderly and makes them reflect on the help of younger people.

Undergraduate students of Araraquara Dental School directed the theater play. Rehearsals were performed during two months focusing in theater technics theater makeup and voice projection. The costumes were selected to match the character's age and characteristics.

The scene was elaborated to be easy to transport, and it was constituted by two banners stamped with a picture of a room with old mobile and wallpaper, as well as old scene accessories, like chairs, a center table, a tray with teacups, a suitcase and a portrait. Objects that were adapted in the local was also used (Figure 2).

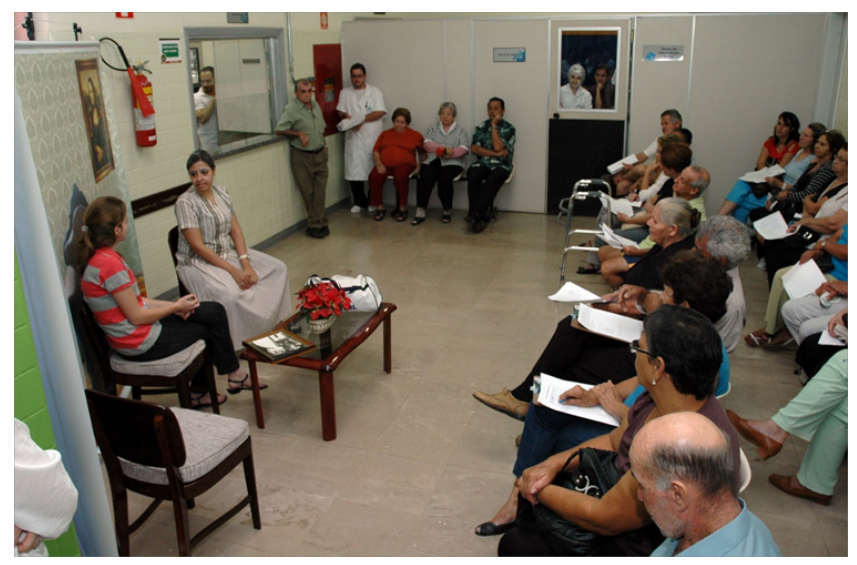

Figure 2 Objects that were adapted in the local was also used.

\section{Study Variables}

The participants filled out a quiz with the same content before and after the theater presentation. The collected variables in the quiz were:
Sociodemographic data: age, schooling in complete years, gender, lifestyle (lives alone, with the spouse, with children, others) and marital status were collected initially to describe the study population.

Specific knowledge: composed by nine questions about themes such as quality of life, aging, habits and oral health (Table 1) and 12 questions about oral diseases and wear of prosthesis (Table 2). The assessment of oral health knowledge followed the methodology adopted by Reed et al. ${ }^{15}$ and Oliveira ${ }^{16}$ with the right answers were distributed.

Scores 1 to 3 were attributed to each possible learning situation according to the answers of the elderly to each question initially (T0answered right both times (prior knowledge).and after the theater presentation (T1), given the learning level of the elderly. Score 1 was attributed to individuals who answered wrong in the first time and right after the presentation (new knowledge Score 2, to answers incorrect in both times (there was no learning), and Score 3 when they didn't know the answer any time, answered right the first time and wrong after the presentation, or were undecided (undecided or wrong change of opinion).

One hundred and eighteen elderly attended six presentations but 18 participants did not respond adequately the answers, totalizing 100 elderly's questionnaire fully completed.

In order to evaluate the acquisition of knowledge after the performance of the activity, from the answers considered as expected, the rightness degree was verified from the first (T0) to the second (T1) moment; the data were analyzed by a descriptive statistic.

\section{Results}

The answers of 100 elderly were evaluated; the mean age was 71.5 years (60-91 years), the majority was females $(75 \%) ; 38 \%$ of the participants reported that they live with their spouse, $12 \%$ live alone, $20 \%$ with their children and 30\% described themselves in another housing condition. Additionally, $37 \%$ of the sample did not complete elementary school, $38 \%$ completed elementary education, $10 \%$ completed high school and $4 \%$ completed higher education.

Table 1 shows the summarized percentage of learning level, according to habits, aging, health, and quality of life, score 1 representing new learning, score 2 for previous learning, score 3 when there was no learning, and score 4 for a situation of indecision or wrong change of opinion.

In table 1 the question "Loss of teeth is a natural consequence of aging" had the highest percentage of new learning (32\%), which shows the theater presentation as a source of information, capable of change cultural concepts such as losing teeth as part of aging. This change of concept is reflected in the question "As you get older, you no longer need to go to the dentist" which had the second highest percentage of new learning with $22 \%$.

Table 2 shows the summarized percentage of learning level according to the responses of oral diseases (caries, periodontal disease, and oral cancer) and wear of prostheses.

Even with specific concepts of oral diseases, a significant percentage of new learning has been identified, such as the question "Elder's teeth are less likely to decay (spoil) than young people's 
teeth" when $73 \%$ of hits were identified, and $31 \%$ of these hits were new learning.

Considering the overall responses, of the 2,100 learning possibilities, $17.9 \%$ were classified as a new learning, $69.3 \%$ of the correct answers were already known and had the concepts maintained, $14.8 \%$ did not have the concepts correctly answered at the end and $4.9 \%$ changed their minds or were undecided strengthened the importance of a playful way of learning.

Table I Percentage of learning level score, considering the topics related to habits, health, aging and quality of life

\begin{tabular}{lcccc}
\hline Questions knowledge score* & T0 & TI & TI & TI \\
\cline { 2 - 4 } A good oral health is important for good general health & PK & NK & NL & WC \\
\hline As you get older, you no longer need to go to the dentist & 93.0 & 5.0 & -- & 2.0 \\
People need to go to the dentist only when they feel something different, like pain & 72.0 & 22.0 & 3.0 & 3.0 \\
The better we live, the better we grow old. & 76.0 & 17.0 & 2.0 & 5.0 \\
Good oral health can bring better quality of life for the elderly & 94.0 & 2.0 & -- & 4.0 \\
Some types of medicines interfere with oral health, such as those that control blood pressure & 48.0 & 32.0 & 16.0 & -- \\
Loss of teeth is a natural consequence of aging & 98.0 & 1.0 & 4.0 \\
I have health if I do not have any disease & 30.0 & 32.0 & 27.0 & 11.0 \\
Every elderly person has dry mouth. & 6.0 & 20.0 & 67.0 & 7.0 \\
Total & 45.0 & 30.0 & 17.0 & 8.0
\end{tabular}

*(I-NK) New knowledge, (2-PK) Prior knowledge, (3-NL) There was no learning, (4-WC) Undecided or wrong change of opinion.

Table 2 Percentage of the learning level scores, considering questions of oral diseases (caries, periodontal disease and oral cancer) and wear of prostheses

\begin{tabular}{|c|c|c|c|c|}
\hline \multirow{2}{*}{ Questions } & \multicolumn{4}{|c|}{ Knowledge score* } \\
\hline & I & 2 & 3 & 4 \\
\hline Caries is the most common oral disease and can be prevented & 3.0 & 97.0 & -- & -- \\
\hline Eating sweets several times a day does not interfere with our oral health & 19.0 & 55.0 & 21.0 & 5.0 \\
\hline Elder's teeth are less likely to decay (spoil) than the teeth of young people & 31.0 & 42.0 & 21.0 & 6.0 \\
\hline Gum bleeding is caused by the accumulation of bacteria (bacterial biofilm). & 13.0 & 83.0 & 2.0 & 2.0 \\
\hline A loose tooth lost the bone that supported it because of an infection (periodontitis). & 18.0 & 76.0 & 4.0 & 2.0 \\
\hline $\begin{array}{l}\text { Those who have diabetes may have difficulties to control the disease if they have a mouth infection such } \\
\text { as periodontitis. }\end{array}$ & 17.0 & 72.0 & 6.0 & 5.0 \\
\hline An infectious disease in the mouth can be a major risk for heart disease. & 17.0 & 80.0 & 1.0 & 2.0 \\
\hline The prosthesis should be brushed only once a day not to wear & 15.0 & 80.0 & 3.0 & 2.0 \\
\hline Who wear complete dentures should sleep with them in the mouth & 29.0 & 58.0 & 10.0 & 3.0 \\
\hline Well-made prostheses need to be adjusted or changed periodically & 24.0 & 65.0 & 16.0 & 5.0 \\
\hline Lack of teeth or prostheses can lead to difficulties in chewing food such as fruits and vegetables & 1.0 & 93.0 & 2.0 & 4.0 \\
\hline Self-examination can prevent oral cancer & 7.0 & 92.0 & -- & 1.0 \\
\hline Total & 16.2 & 74.4 & 6.4 & 3.0 \\
\hline
\end{tabular}

*(I-NK) New knowledge, (2-PK) Prior knowledge, (3-NL) There was no learning, (4-WC) Undecided or wrong change of opinion. 


\section{Discussion}

The aim of this study was to evaluate the learning related to oral and multidisciplinary health concepts of interest to the elderly who attended a theatrical play involving educational concepts. The null hypothesis was rejected since the theatrical presentation was able to incorporate new knowledge into the target population, although the results were limited to this group.

The studied population presented a high level of prior knowledge since $69.3 \%$ of all questions were correctly answered by the group before theater presentation. The previous knowledge could be considered high, although the questions had $16.9 \%$ of new answers with only one presentation, characterizing a new learning.

For the questions regarding to habits, health, aging and quality of life, previous knowledge was lower $(62.4 \%)$, considering issues related to oral diseases and wear of prostheses $(74.4 \%)$, which in this case presented lower retention of new knowledge (16.2\%) compared to the questions in table 1 that obtained $17.9 \%$ of new knowledge. These questions showed, after the activity, a higher prevalence of errors $(14.8 \%)$ and indecision or erroneous change of opinion $(4.9 \%)$ in relation to issues that include specific concepts of oral health and wear of prostheses, with values of $6.4 \%$ and $3 \%$ respectively.

Specifically, when asked if some medications interfere with oral health, $48 \%$ of them correctly answered the question and after the activity, this percentage increased to $80 \%$, with a new knowledge gain of $32 \%$. Oliveira ${ }^{18}$ obtained $75.7 \%$ of correct answers for this question in a cross-sectional study carried out among elderly caregivers; showing that through the theater as a teaching tool, higher levels of learning were obtained, taking into account the difference of studied population.

As the relationship among health and illness, $81 \%$ of the elderly mistakenly believe that they would have health only if no illness was present. The World Health Organization defines health not only the absence of disease but rather as a state of mental, social and physical well-being. ${ }^{19}$ After the activity, $72 \%$ of the elderly remained with this false concept, although initially a correct answer was given by $9 \%$ of the elderly, and later, $25 \%$ of them correctly answered that question.

Another issue that deserves to be highlighted is that initially, 50\% of the elderly showed belief in the concept that tooth loss is a natural consequence of aging, after the activity this percentage dropped to $35 \%$, showing a new learning of $32 \%$ in this topic.

Oliveira ${ }^{16}$ studied 70 elderly caregivers, $51.4 \%$ of them stated that tooth loss is a natural consequence of aging, similar to the $50 \%$ value initially obtained in this study. Reed et al. ${ }^{15}$ also obtained a similar result among caregivers for this question (initially 56.3\%), and after educational multimedia activities, all replied correctly. These two studies, although performed in different target populations, partly reflect the misconception that lay people have about tooth loss since aging is not a determining and imposing factor for tooth loss. Health programs should demystify dental loss as something that is unavoidable or even irrelevant to the individual's well-being. ${ }^{18}$ stressing the importance of professional attention to the fact that the tendency of natural teeth to be retained during aging. ${ }^{3}$

Questions related to oral diseases (caries, periodontal disease, and oral cancer) and the wear of prostheses included the concept that teeth of the elderly are also at risk of caries, emphasizing the importance of root caries; this issue initially presented $48 \%$ of hits, which increased to $70 \%$ after the activity. Concepts such as the fact that eating candy several times a day interferes with oral health $(58 \%)$, those who wear complete dentures should not sleep with them (58\%), and that even well-fitted prostheses need periodic adjustments or changes (71\%) were the ones that showed the lowest frequencies of initial hits, but with second-chance scores of $73 \%, 86 \%$ and $88 \%$, respectively. Additionally, at the end of the activity, all the participants agreed that caries is the most common oral disease and can be avoided and selfexamination can prevent oral cancer.

In a study with elderly caregivers, $82.4 \%$ agreed that the prosthesis should be removed for sleep and $80 \%$ that even fit dentures needs periodic adjustments, and after educational activity, all of them correctly answered these questions. ${ }^{17}$ In another study, $61.4 \%$ of the 70 caregivers investigated recognized that prostheses should be taken off during the night, and only $47.1 \%$ felt they needed a periodic visit to the dentist for maintenance or replacement when they were wellmade. ${ }^{16}$

Although the literature is scarce regarding studies of motivational and educational techniques in elderly oral health, it is unanimous in emphasizing the importance of education in behavior change, in the need for continuous learning and in health promotion. ${ }^{1-3,19}$ Thus, in spite of the scientific advances in the various specialties of dentistry, the success of the treatments and the maintenance of the oral health are supported directly or indirectly in the education for the health.

However, the low relevance attributed to health education and the consequent weakening of educational practices are related to a set of interrelated factors. The training of dental surgeons focuses predominantly on clinical treatment and the development of communication and expression becomes restricted. ${ }^{1}$ In addition, the concept of care for the individual rather than the disease should be clearly established in the professional training of the dental surgeon ${ }^{5}$ and education must be a permanent process of knowledge construction. The same concept should be applied in the education of the elderly, who have physical and emotional specificities that must be respected and preserved during the educational process; the programs must be specific, measurable, appropriated to the needs of the group, realistic and with a measurement time interval. ${ }^{20}$

Additionally, in a study with patients with chronic renal failure, the play activities were explored and positively influenced the patients' life's, providing them with well-being, feelings of emotion, nostalgia, and self-esteem. ${ }^{9}$ Other studies showed the efficiency of this type of activity being used for health education, creating a bridge between scientific knowledge and leisure ${ }^{11}$ Campos $^{12}$ shows that the use of theater presentation as an instrument of education is not only efficient but also pleasurable for this age group and self-affirmative. ${ }^{21}$

Educational activities for the elderly should also emphasize selfprotection and self-perception ${ }^{19}$ and should consider the importance of discussing health concepts in an integrated way ${ }^{5}$, raising the awareness of professional staff about health promotion messages. ${ }^{6}$

In this study, the theatrical play applied in the educational process sought to maintain identification with the elderly, addressing specific themes and emphasizing health promotion, although the results were only verified immediately after the activity.

Although the limitations of this study such as the sample size, the profile of the population and the period of assessment, immediately after the educational activity, the theatrical educational practice 
adopted was capable to add new knowledge in the area of health promotion to the elderly group. More studies should be done in the elderly with different characteristics and with more presentations in order to evaluate the construction of continuous knowledge at various intervals and with interactive and diverse methodologies. ${ }^{22}$

\section{Conclusion}

The theatrical play activity is a method capable of adding new knowledge in oral health to the elderly. This method was pleasurable for them and it was able to integrate the student to the elderly in order to build the new knowledge and to value the human being.

\section{Acknowledgements}

Adriana Alves de Faria, Fernanda Alves Dias de Souza and Fernanda da Silveira Vargas Regatieri for the performance on the Theater.

\section{Conflict of interest}

Author declares that there is no conflict of interest.

\section{References}

1. Buischi YP. Promoção de Saúde Bucal na Clínica Odontológica. São Paulo: Artes Médicas, 2000:336.

2. Cangussu MCT, Magnavita R, Rocha MCBS. Educação e construção da cidadania em um programa de saúde bucal em Salvador -Ba. Rev Aboprev. 2001;4:15-20.

3. Shinkai RSA, Del Bel Cury AA. O papel da odontologia na equipe interdisciplinar: contribuindo para a atenção integral ao idoso. Cad Saúde Pública. 2000;16:1099-109.

4. Tomita NE, Pernambuco RA, Llauris JRP, et al. Educação em saúde buca para adolescentes: uso de métodos participativos. Rev Fac Odontol Bauru. 2001;9:63-69.

5. Sheiham A. Public health approaches to promoting periodontal health. Rev Bras Odontol Saúde Coletiva. 2001;2:61-82.

6. Sinkoç CR. Educação em saúde bucal e a motivação do paciente. Rev Odontol Univ Santo Amaro. 2001;6:40-43.

7. Silva SRC, Castellanos FRA. Percepção de Saúde bucal. Rev Saúde Pública. 2001;35;349-355.

8. Poppe B, Krzikalla G, Walde B. Collective measures of oral hygiene effects on dental health in elder school children. Dtsch Stomatol. 1991;41(5):181183.

9. Brasil MLS, Schwartz E. As atividades lúdicas em unidade de hemodiálise. Acta Science Health Science. 2005;27:9-18.

10. Beuter M, Cordeiro FR, Quinhones SMW, et al. O teatro como estratégia lúdica no cuidado ao doente hospitalizado. Rev enferm UFPE on line. 2010;4(1):401-404

11. Soares SM, Silva LB, Silva PAB. O Teatro em Foco: Estratégia lúdica para trabalho educativo na saúde da família. Esc Anna Nery (impr.). 2011; (4):818-824.

12. Campos CNA, Santos LC, Moura MR, et al. Reinventando práticas de enfermagem na educação em saúde: Teatro com idosos. Esc Anna Nery. 2012;16(3):588-596.

13. Andrade HH, Mello MB, Sousa MH, et al. Changes in sexual behavior following a sex education program in Brazilian public schools. Cad Saude Publica. 2009;25(5):1168-1176.

14. Montandon AAB, Rosell FL. Odontogeriatria: reaprendendo o atender e o cuidar. In: Jeanete LM, Ivone P, editors. (Org.). Na Intimidade da Velhice. 1sted . Holambra. SP: Editora Setembro. 2006;1:111-122.

15. Reed R, Broder HL, Jenkins G, et al. Oral health promotion among older persons and their care providers in a nursing home facility. Gerontology. 2006;23(2):73-78

16. Oliveira CSR. Avaliação das condições de saúde bucal, autopercepção e conhecimento de cuidadores de idosos institucionalizados. Piracicaba, SP; 2008 .

17. World Health Organization (WHO). Constitution of WHO: principles; 2018.

18. Unfer B, Saliba O. Avaliação do conhecimento popular e práticas cotidianas em saúde bucal. Rev Saúde Pública. 2000;34:190-195

19. Alves PA, Silva RL, Souza HA. Conhecimentos de Higiene Bucal de idosos atendidos nas clínicas das Instituições Públicas de Ensino Superior de Odontologia em Pernambuco. Odontologia Clin Cientif Recife. 2007;6:219-222.

20. Sarin J, Balasubramaniam R, Corcoran AM, et al. Reducing the risk of aspiration pneumonia among elderly patients in long-term care facilities through oral health interventions. J Am Med Dir Assoc. 2008;9(2):128135 .

21. Watt RG, Fuller S, Harnett R, et al. Oral health promotion evaluation - time for development. Community Dent Oral Epidemiol. 2001;29(3):161-166.

22. Kay EJ, Locker D. Is dental health education effective? A systematic review of current evidence. Community Dent Oral Epidemiol. 1996;24(4):231235 . 